\title{
Retenção das Habilidades de Ressuscitação Cardiopulmonar nos Estudantes de Medicina
}

\author{
Retention of Cardiopulmonary Resuscitation Skills in Medical Students
}

Miguel Antônio Moretti, ${ }^{10}$ Adriana de Oliveira Camboim, ${ }^{1}$ Caroline Awoki Ferrandez, ${ }^{1}{ }^{\circledR}$ Isabela Corralo Ramos, ${ }^{1}{ }^{\circledR 0}$ laggo Bemini Costa, ${ }^{1}$ Juliana Seidler Canonaco, ${ }^{10}$ Vanessa Lopes Mathia, ${ }^{1}{ }^{\circledR}$ João Fernando Monteiro Ferreira, ${ }^{1}$ Antonio Carlos Palandri Chagas ${ }^{1}$

Faculdade de Medicina da Fundação do ABC - Cardiologia, ${ }^{1}$ Santo André, SP - Brasil

\section{Resumo}

Fundamento: A redução da mortalidade e das sequelas de uma vítima de parada cardíaca depende de um atendimento eficaz, rápido e iniciado o mais precocemente possível. O suporte básico de vida (SBV) compreende uma série de etapas que podem ser iniciadas fora do ambiente hospitalar, e ensinadas para qualquer pessoa em cursos específicos. Porém, é importante que o socorrista retenha o conhecimento e as habilidades, pois nunca se sabe quando será necessário realizar uma ressuscitação cardiopulmonar (RCP). Entretanto, estudos mostram que existe uma perda das habilidades em executar uma RCP já com 30 dias após o treinamento, com variações segundo algumas características das pessoas e da atividade profissional.

Objetivo: Avaliar se os estudantes de medicina são capazes de reter as habilidades por mais de seis meses.

Métodos: Estudo prospectivo, caso controle, observacional. Estudantes de medicina realizaram um curso sobre morte súbita e parada cardíaca de $\mathbf{4 0}$ horas. A avaliação das habilidades foi realizada imediatamente após o curso e seis meses depois. Foram comparadas as notas individuais entre dois momentos, foi avaliada a porcentagem de acerto em cada etapa e uma análise global do atendimento foi classificado como ótimo, bom e ruim. Os avaliadores e critérios foram os mesmos nos dois momentos. Os dados foram analisados pelos teste-t pareado e teste de McNemar, onde para um nível de confiança de $95 \%$ o critério para significância foi $p<0,05$.

Resultados: Cinquenta estudantes (27 do sexo feminino) do primeiro ano, com idade entre 18 e 24 anos (média 21 ), realizaram o curso. O número de etapas cumpridas de forma correta após seis meses foi significativamente menor que logo após o curso $(10,8$ vs 12,5 p $<0,001)$. O sexo e idade não interferiram nos resultados. A qualidade global foi considerada ótima em $\mathbf{7 8} \%$ dos atendimentos realizados logo após o curso, significativamente, maior que os $40 \%$ após seis meses $(p<0,01)$. Após seis meses, maior número de erros foi observado nas etapas relacionadas às habilidades mais práticas (como posicionamento das mãos).

Conclusão: Seis meses após o curso observamos uma perda significativa das habilidades, entre estudantes de medicina, prejudicando a eficácia global do atendimento.

Palavras-chave: Reanimação Cardiopulmonar; Mortalidade; Parada Cardíaca; Estudantes de Medicina; Educação; Aprendizagem; Habilidade.

\section{Abstract}

Background: Reduction of mortality and sequelae of cardiac arrest depends on an effective and fast intervention, started as soon as possible. Basic life support involves a series of steps that may be initiated out of the hospital setting and taught to any person in specific courses. However, it is important that the rescuers retain the knowledge and skills to perform cardiopulmonary resuscitation (CPR), as one never knows when they will be required. Studies have shown that a loss of skills occurs as early as 30 days after the training course, with variations according to personal and professional characteristics.

Objectives: to assess whether medical students are able to retain skills acquired in a BLS course for more than six months.

Methods: Prospective, case-control, observational study. Medical students attended a 40-hour course on sudden death and cardiac arrest. Skills acquired during the course were evaluated immediately after and six months after the course. Students' individual scores were compared between these time points, the percentage of correct answers was evaluated, and overall performance was rated as excellent, good, and poor. Observers and evaluation criteria were the same immediately after the course and six months later. Data were analyzed using the paired t-test and the McNemar test. The 95\% confidence interval was established, and a $p<0.05$ was set as statistically significant.

Correspondência: Miguel Antônio Moretti •

Faculdade de Medicina da Fundação do ABC - Av. Príncipe de Gales, 821. CEP 09060-650, Santo André, SP - Brasil

E-mail: mamorett@uol.com.br

Artigo recebido em 27/05/2020, revisado em 19/10/2020, aceito em 02/12/2020

DOI: https://doi.org/10.36660/abc.20200546 
Results: Fifty students (27 female) in the first year of medical school aged from 18 to 24 years (mean of 21 years) attended the course. The number of steps successfully completed by the students at six months was significantly lower than immediately after the course (10.8 vs $12.5 p<0.001)$. Neither sex nor age affected the results. Overall performance of $78 \%$ of the students was considered excellent immediately after the course, and this percentage was significantly higher than six months later ( $p<0.01)$. After six months, the steps that the students failed to complete at six months were those related to practical skills (such as a correct hand positioning).

Conclusion: A significant loss of skills was detected six months after the BLS course among medical students, compromising their overall performance.

Keywords: Cardiopulmonary Resuscitation; Mortality; Heart Arrest; Medical Students; Education; Learning; Hability.

Full texts in English - http://www.arquivosonline.com.br

\section{Introdução}

As doenças isquêmicas do coração são as principais causas de morte por doenças cardiovasculares, ${ }^{1}$ morte súbita (MS), e de parada cardiorrespiratória $(P C R)^{2}$ na população brasileira. A tentativa de reversão da PCR é feita por manobras de ressuscitação cardiopulmonar (RCP) e a redução da mortalidade e de sequelas de uma vítima de PCR depende de um atendimento eficaz, rápido e mais precoce possível, de preferência no local de sua ocorrência. ${ }^{2,3}$

O suporte básico de vida (SBV) compreende uma série de etapas que podem ser iniciadas fora do ambiente hospitalar., ${ }^{4,5}$ Em um curso de SBV, as técnicas de RCP abordadas vão desde o reconhecimento precoce da parada cardíaca, do início imediato das manobras de compressão torácica e ventilação, até o uso do desfibrilador externo automático (DEA), e podem sem ensinadas para qualquer pessoa..$^{5-7}$ Como a maioria dos eventos de PCR ocorre fora do ambiente hospitalar, é importante que a população saiba executar as técnicas de $\mathrm{RCP}^{8-10}$ mesmo que as pessoas achem que somente os profissionais da área da saúde sejam capazes de agir adequadamente em emergências.

Contudo, não basta apenas um treinamento adequado; é importante que o socorrista retenha o conhecimento e as habilidades para manter a eficiência da RCP, pois nunca se sabe quando será necessário colocar esses conhecimentos em prática. Diversos estudos foram realizados para avaliar a capacidade de retenção dessas informações e habilidades ao longo do tempo. ${ }^{11,12}$ No entanto, eles não são unânimes em apontar as principais causas da queda na retenção e nem em quanto tempo isso acontece. Isso dificulta, por exemplo, estabelecer com qual periodicidade deve-se realizar o retreinamento.

Estudos mostram que, mesmo entre profissionais da saúde existe uma perda das habilidades em executar uma RCP e apontam como causas desse insucesso o treinamento insuficiente e/ou falta de retenção de habilidades. ${ }^{13}$ Mesmo esses profissionais, às vezes, passam muito tempo sem utilizar esses conhecimentos. Smith et al., ${ }^{11}$ demonstraram que as habilidades psicomotoras na RCP têm uma queda após 10 semanas em estudantes de graduação em enfermagem, e outros estudos destacam que as habilidades práticas se deterioraram já a partir dos primeiros 30 dias após o curso de suporte de vida avançado (SVA) e essa perda vai se acentuando até se estabilizar ao final de um ano. ${ }^{14}$ Estudo publicado em 2014 ressalta uma redução na retenção de habilidades entre estudantes de medicina após um e dois anos do curso de RCP. ${ }^{15,16}$
Como qualquer pessoa, os estudantes de medicina também estão sujeitos a testemunharem eventos de MS ou de PCR fora do ambiente hospitalar, o que já justificaria um treinamento sobre manobras de RCP. ${ }^{17,18}$ Desde seu ingresso na faculdade, logo nos primeiros meses, os estudantes já são cobrados pela sociedade e por eles mesmos a agirem como médicos, esperando que tenham as mesmas habilidades de um profissional. ${ }^{19,20}$ Por isso, defendemos que o treinamento para o atendimento à PCR faça parte do currículo do curso de medicina, ${ }^{12}$ onde o SBV seria ensinado logo no primeiro ano e o SVA mais no final do curso quando o estudante já possui uma carga maior de conhecimento, habilidades e logo estará trabalhando na assistência a pessoas. Entendemos que os cursos do American Heart Association (AHA) - por exemplo, o Basic Life Support (BLS) e o Heart Saver - e da Sociedade Brasileira de Cardiologia (Treinamento de Emergências Cardiovasculares Básico - TECA B) atendem as necessidades do treinamento para profissionais da saúde já formados ou para uma população leiga. Mas, para os estudantes do primeiro ano de medicina, o curso básico deveria incluir não somente o treinamento de habilidades, mas também proporcionar uma base teórica mais ampla, para que o aprendizado seja mais fácil e a retenção das habilidades aprendidas de maneira mais duradoura ${ }^{12,17}$.

Nossa hipótese é de que a perda de conhecimento e de habilidades para realizar as manobras de RCP já está presente entre estudantes de medicina seis meses após um treinamento de SBV, mesmo no caso de cursos mais elaborados e de maior duração.

\section{Metodologia}

Cinquenta estudantes (27 do sexo feminino) do primeiro ano da graduação do curso de medicina, com idade entre 18 e 24 anos (média 21), realizaram o curso de "Morte Súbita e Ressuscitação Cardiopulmonar". Esse é um curso optativo dentro da grade curricular da graduação com carga horária de 32 horas-aula, sendo cerca de 30\% de aulas teóricas e 70\% de aulas práticas, com ênfase no desenvolvimento de habilidades e simulações de situações de MS e/ou PCR.

Além de um conteúdo teórico sobre a história, epidemiologia e fisiopatologia da MS, o curso também contempla uma parte prática onde os alunos são treinados para executar o atendimento a uma situação de PCR. Durante as aulas práticas são desenvolvidas e treinadas habilidades como reconhecer os sinais de uma PCR e quais atitudes tomar - verificar a segurança do local, saber quem e como chamar ajuda, como 
executar uma compressão torácica eficiente (força, frequência, profundidade, localização e posicionamento das mãos), como executar uma ventilação segura e eficaz utilizando dispositivos adequados, identificar a necessidade do uso de um DEA, como utilizá-lo e como dar sequência ou decidir pela interrupção do atendimento. Esse treinamento prático é baseado nos cursos de padronização do atendimento da PCR recomendado pela $\mathrm{AHA}^{16}$ (o BLS) e pela Sociedade Brasileira de Cardiologia (o TECA B). ${ }^{5}$

Após o curso, os estudantes tiveram os conhecimentos e as habilidades para o atendimento de uma PCR avaliados em ambiente extra-hospitalar. Para tanto, foi utilizada uma ficha padronizada com etapas que deveriam ser cumpridas de forma correta (Quadro 1).

Cada etapa realizada pelo aluno foi avaliada como cumprida ou não (SIM se realizou de forma correta e NÃO se não realizou de forma correta, ou se não realizou). Ao final, o atendimento como um todo (atendimento global) foi avaliado em: ótimo, bom ou ruim. Para um ótimo desempenho, o aluno poderia cometer até dois erros (o que estaria acima dos $84 \%$ de acertos que é exigido pelo $\mathrm{AHA}^{16}$ ); para um bom desempenho, três ou quatro erros (mais de $70 \%$ de acertos); e ruim se cometesse mais de quatro erros (menos de 70\% de acertos). Setenta por cento de acertos é o mínimo esperado para o aluno ser aprovado no curso de acordo com os critérios da faculdade.

Após seis meses do curso, os estudantes foram submetidos a uma reavaliação, onde realizaram um atendimento simulado de PCR em manequim, sem agendamento prévio. Foi utilizada a mesma ficha de avaliação e os mesmos critérios (mesmos instrutores/professores). O atendimento global também foi classificado.

Todos os alunos assinaram termo de consentimento livre e esclarecido aceitando participar do estudo. O estudo, a aprovação pelo comitê de ética e o termo de consentimento livre e esclarecido foram aprovados e registrados na Plataforma Brasil (CAAE: 81721317.7.0000.0082).

\section{Análise Estatística}

Trata-se de um estudo prospectivo, onde cada indivíduo foi controle dele mesmo, em uma amostra por conveniência. Quando se comparou etapa por etapa, os resultados foram avaliados pelo teste de McNemar para as variáveis categóricas (apresentadas em valores absolutos e em porcentagem). As médias e desvios padrões das variáveis contínuas foram comparadas pelo teste t pareado usando o programa Excel da Microsoft Office $365^{\text {tw }}$, após confirmação da normalidade pelo teste de Shapiro-Wilk. O nível de confiança de 95\% foi calculado e valor de $p$ menor que 0,05 foi estabelecido para significância estatística.

\section{Resultados}

Todos os alunos foram avaliados logo após o curso e seis meses depois. Das 14 etapas avaliadas, os estudantes cumpriram de forma correta, em média, 12,5 etapas logo após o curso e em média 10,8 etapas na avaliação após seis meses. Houve uma diferença significativa ( $p<0,001)$, demonstrando uma perda na retenção do conhecimento e das habilidades após o período de seis meses. Também observamos que, apesar de os homens terem uma média de idade maior que as mulheres (21,7 anos vs. 20,2 anos $-\mathrm{p}=0,006)$, a idade e o sexo dos alunos não interferiram de forma independente no resultado das avaliações. Os homens tiveram uma redução de acertos (12,8 acertos antes e 10,9 acertos depois) significativa ( $p=0,003)$, assim como as mulheres (12,2 acertos antes e $10,7$ acertos depois) significativa ( $p=0,013)$. Na avalição do atendimento global, também foi observado uma piora

Quadro 1 - Formulário usado para avaliar conhecimento e habilidades adquiridos no curso "Morte Súbita e Ressuscitação Cardiopulmonar" aplicado imediatamente após e seis meses depois do curso

ETAPAS A SEREM EXECUTADAS APÓS IDENTIFICAR UM INDIVÍDUO INCONSCIENTE, QUE NÃO SE MEXE E NÃO RESPIRA

Avaliar a segurança do local e da execução de atendimento

Solicitar ajuda a outra pessoa de forma clara e objetiva, dizendo o que é para fazer

Definir para quem ligar - 192/193

Solicitar o desfibrilador externo automático (DEA)

Colocar vítima na posição correta e verificar pulso e respiração

Iniciar compressões torácicas de imediato

Colocar as mãos na posição correta sobre o esterno

Exercer cada compressão na profundidade correta $(4-5 \mathrm{~cm})$

Exercer compressões na frequência correta (100 vezes por minuto)

Realizar ventilação somente com dispositivo de proteção

Manter os 5 ciclos de 30 compressões e 2 ventilações antes de reavaliar a vítima

Não interromper a ressuscitação cardiopulmonar na chegada do DEA

Utilizar o DEA de acordo com instruções do aparelho

Retomar as manobras de ressuscitação (RCP) após uso do DEA se necessário 
significativa na qualidade do atendimento, com 39 (78\%) atendimentos considerados ótimos logo após o curso e 20 (40\%) atendimentos considerados ótimos seis meses após ( $p<0,01)$. As porcentagens de alunos que executaram de forma correta cada etapa avaliada logo após o curso e na reavaliação após seis meses encontram-se na Tabela 1 e Figura 1.

\section{Discussão}

O nosso estudo demonstrou uma redução significativa ( $p<0,01$ ) das habilidades para o atendimento da PCR. Os alunos completaram corretamente, em média, 12,5 etapas do atendimento logo após o curso contra 10,8 etapas corretas

Tabela 1 - Resultado da avaliação do conhecimento adquirido no curso “Morte Súbita e Ressuscitação Cardiopulmonar”, por número e porcentagem de alunos que cumpriram cada etapa, logo após o curso e seis meses depois

\begin{tabular}{lccc}
\hline \multirow{2}{*}{ Etapa } & \multicolumn{2}{c}{$\begin{array}{c}\text { Porcentagem de alunos que realizaram } \\
\text { de forma correta }\end{array}$} & \multirow{2}{*}{$\mathbf{P}^{*}$} \\
\cline { 2 - 3 } & \multicolumn{1}{c}{ Imediato (N) } & Seis meses (N) & 0.307 \\
\hline 1 - Avaliar a segurança & $42(21)$ & $54(27)$ & 0.683 \\
\hline 2 - Solicitar ajuda & $88(44)$ & $84(42)$ & $\mathbf{0 . 0 0 2}$ \\
\hline 3 - Definir para quem ligar & $94(47)$ & $68(34)$ & 0.181 \\
\hline 4 - Solicitar o DEA & $92(46)$ & $80(40)$ & 0.683 \\
\hline 5 - Verificar pulso e ventilação & $96(48)$ & $92(46)$ & 0.248 \\
\hline 6 - Iniciar compressões torácicas & $100(50)$ & $94(47)$ & $\mathbf{0 . 0 1 0}$ \\
\hline 7 - Colocar as mãos na posição correta & $90(45)$ & $66(33)$ & 0.289 \\
\hline 8 - Profundidade correta da compressão & $96(48)$ & $88(44)$ & 0.264 \\
\hline 9 - Frequência correta das compressões & $82(41)$ & $70(35)$ & $\mathbf{0 . 0 1 0}$ \\
\hline 10 - Realizar ventilação com dispositivo de proteção & $88(44)$ & $62(31)$ & $\mathbf{0 . 0 0 2}$ \\
\hline 11 - Manter os 5 ciclos de 30:2 antes de reavaliar & $100(50)$ & $76(38)$ & $\mathbf{0 . 0 4 1}$ \\
\hline 12 - Não interromper a RCP na chegada do DEA & $100(50)$ & $88(44)$ & 0.387 \\
\hline 13 - Utilização do DEA de acordo com instruções & $88(44)$ & $80(40)$ & 0.387 \\
\hline 14 - Retomar RCP após uso do DEA se necessário & $92(46)$ & $84(42)$ & \\
\hline
\end{tabular}

* valor de p calculado pelo teste de McNemar (bicaudal); RCP: ressuscitação cardiopulmonar; DEA: desfibrilador externo automático.

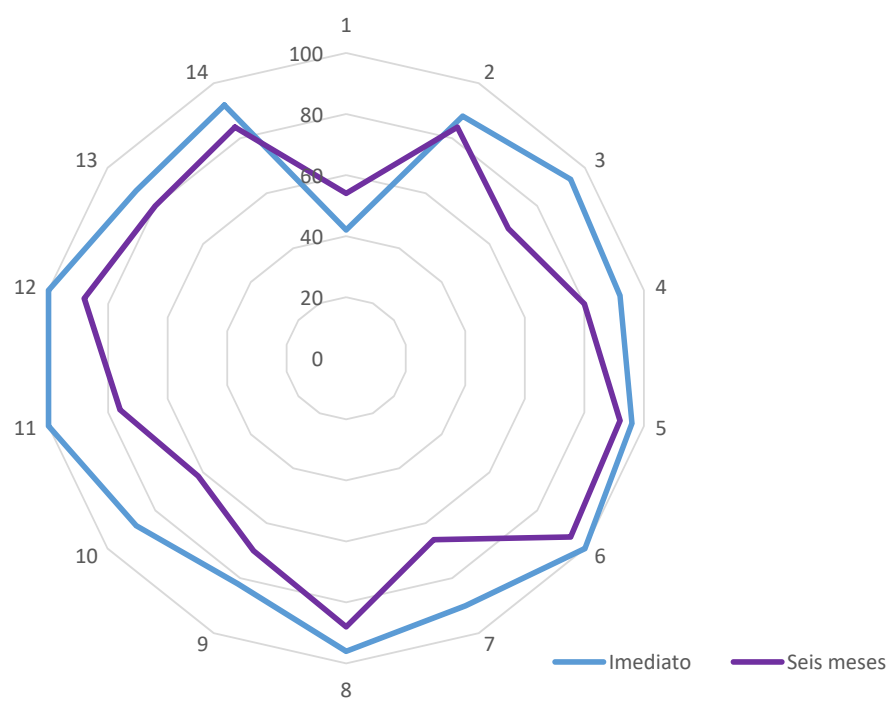

Figura 1 - Porcentagem de alunos que executaram de forma correta as etapas do atendimento, imediatamente após o curso e seis meses depois. A numeração corresponde à adotada na Tabela 1. 
após seis meses. Enquanto 39 estudantes (78\%) completaram corretamente mais de 12 das 14 etapas do atendimento simulado logo após o curso, apenas 20 (40\%) atingiram o mesmo escore após seis meses do curso.

Nós avaliamos somente o aspecto referente às habilidades necessárias para um atendimento adequado e correto da PCR e observamos ao final do curso que os alunos demonstraram ter aprendido de forma satisfatória essas habilidades. Apenas a primeira etapa, onde eles deveriam checar a segurança antes de iniciar o atendimento, não foi realizada de forma correta pela maioria dos estudantes (42\%). Quando questionados sobre isso, os estudantes alegaram que como estavam em uma sala de aula, atendendo um manequim estático e num ambiente já sabidamente seguro eles se esqueciam de checar a segurança. Outra justificativa foi a ansiedade por iniciar rapidamente o atendimento. Mesmo assim, o aproveitamento demonstrado ao final do curso foi adequado ao exigido pela AHA, que deve ser maior que $84 \% .{ }^{16}$ Observou-se também que idade e sexo não interferiram nas notas dos alunos ao final do curso, reforçando que o curso foi um fator importante no aprendizado.

Um problema frequentemente relatado nos estudos sobre ensino do atendimento à PCR é como manter a retenção do que foi ensinado. Uma metanálise ${ }^{14}$ sobre o assunto deixa claro que as habilidades se perdem ao longo do tempo se não praticadas ou exercitadas, iniciando-se com poucas semanas e atingindo um ponto mais elevado de perda com cerca de nove meses há um ano. Esses estudos mostram que o tempo decorrido desde o último treinamento é diretamente proporcional ao grau de perda das habilidades e do conhecimento necessário para atender uma PCR. ${ }^{14}$

Em nosso estudo, observamos que essa perda também acontece de forma significativa com os estudantes de medicina do primeiro ano do curso, com uma perda de aproximadamente $15 \%$ na nota média da prova de habilidades, o que impactou numa perda de cerca de 50\% na qualidade do atendimento global. Não esperávamos que a perda de retenção fosse diferente entre os estudantes de medicina, pois outros estudos com profissionais da saúde ou estudantes demonstram a ocorrência dessa perda, ${ }^{13}$ e por sabermos que os estudantes não praticam ou atendem com frequência eventos de PCR. Na realidade, seria necessário um estudo comparando essa perda entre estudantes de medicina e outros profissionais.

Na população estudada, foi nítida a redução das habilidades. Observamos que as perdas mais significativas foram nas etapas onde as habilidades práticas requerem agilidade e mais atenção. Vários outros estudos também mostraram que essas etapas foram mais esquecidas ou realizadas de forma inadequada. ${ }^{21,22} \mathrm{~A}$ não realização adequada dessas etapas (definir para quem ligar; colocar as mãos de forma correta e no local certo; realizar ventilação com dispositivo de proteção; manter os 5 ciclos e não interromper as manobras com a chegada do DEA) pode favorecer a ocorrência de eventos adversos ou complicações decorrentes do atendimento como, por exemplo, fratura de costelas e compressões ineficientes (que não geram circulação eficiente). ${ }^{23}$
Ainda, nem idade nem sexo interferiu na perda da retenção de conhecimento e habilidades por nossos estudantes, e o tempo parece ter sido o único fator responsável pela perda de retenção. Isso é reforçado pelo fato de que nenhum dos estudantes atendeu eventos de PCR ou auxiliou na administração de cursos de RCP.

Uma estratégia para manter a retenção das habilidades, conforme proposto em outras publicações, ${ }^{17,24}$ seria um retreinamento periódico como, por exemplo, e-learning. Porém, uma questão ainda não respondida seria qual o intervalo e periodicidade do treinamento, qual tipo de treinamento e para qual tipo de população (profissionais da saúde ou não, que atuam em locais com elevada ocorrência de eventos de PCR). Outra questão é se o curso inicial deveria ser mais completo ou mais curto, particularmente para estudantes de medicina. Essa questão seria respondida por um estudo comparativo entre os dois métodos.

A limitação desse estudo está no número de alunos avaliados e por ter sido, apesar de prospectivo, uma observação em um único centro e após um único treinamento. Ruijter et al., ${ }^{15}$ mostraram uma redução significativa das habilidades adquiridas por 120 alunos de medicina um e dois anos após um curso de SBV, semelhante ao que demonstramos. Assim, embora o objetivo tenha sido analisar a retenção das habilidades, nossos resultados foram muito semelhantes aos de outros estudos, essa limitação não compromete a importância do estudo. Outra limitação para aprofundarmos a discussão sobre a retenção e sobre qual seria o melhor tipo de curso é que os conhecimentos teóricos não foram avaliados, apesar de alguns estudos mostrarem que as perdas se dão mais nas habilidades práticas. ${ }^{11}$ Embora os alunos soubessem que seriam reavaliados em algum momento depois do curso, isso parece não ter comprometido o resultado pois muitos deles haviam se esquecido que seriam reavaliados, pois na realidade já haviam sido aprovados no curso. Tal fato, porém, não minimiza a necessidade de os cursos de retreinamento serem mais frequentes, para tentar reduzir a perda das habilidades.

\section{Conclusão}

Seis meses após um curso com treinamento de atendimento simulado a vítimas de MS ou PCR, observamos uma perda significativa das habilidades em estudantes do primeiro ano da graduação em medicina, assim como observado na população que não é da área da saúde. Essa perda foi relacionada com o período em que os estudantes ficaram sem praticar ou sem revisitar as técnicas e o conhecimento de se realizar as etapas da RCP corretamente, e isso prejudica a eficácia do atendimento. Um curso mais robusto parece melhorar o aprendizado, mas ainda assim não melhora a retenção das habilidades. A avaliação do aprendizado e da retenção poderia ser complementada com estudos envolvendo retreinamento e resultado clínico, ou seja, mostrar que treinar e retreinar melhora não só habilidades, mas que também pode salvar mais vidas. 


\section{Contribuição dos autores}

Concepção e desenho da pesquisa: Moretti MA, Camboim AO, Ferrandez CA, Ramos IC, Costa IB, Canonaco JS, Mathia VL, Ferreira JFM. Obtenção de dados: Moretti MA, Camboim AO, Ferrandez CA, Ramos IC, Costa IB, Canonaco JS, Mathia VL. Análise e interpretação dos dados: Moretti MA, Camboim AO, Ferrandez CA, Ramos IC. Costa IB, Canonaco JS, Mathia VL. Análise estatística: Moretti MA. Redação do manuscrito: Moretti MA, Camboim AO, Ferrandez CA, Ramos IC, Costa IB. Canonaco JS, Mathia VL, Ferreira JFM, Chagas ACP. Revisão crítica do manuscrito quanto ao conteúdo intelectual importante: Moretti MA, Ferreira JFM, Chagas ACP.

\section{Potenciais conflitos de interesse}

Declaro não haver conflito de interesses pertinentes.

\section{Referências}

1. Mansur AP, Favarato D. Tendências da Taxa de Mortalidade por Doenças Cardiovasculares no Brasil, 1980-2012. Arq Bras Cardiol. 2016; 107(1):20-5.

2. Gonzalez MM, Timerman S, Gianotto-Oliveira R, Polastri M, Canesin MF Schimidt H, et al. Diretriz de Ressuscitação Cardiopulmonar e Cuidados Cardiovasculares de Emergência da Sociedade Brasileira de Cardiologia. Arq Bras Cardiol 2013;101(2:Supl 3):1-221.

3. Pergola AM, Araujo IE. Laypeople and basic life support. Rev Esc Enferm USP 2009;43(2):335- 42.

4. Ferreira AVS, Garcia E. Suporte básico de vida. Rev Soc Cardiol Estado de São Paulo 2001;11(2):214-25.

5. Timerman S, Canesin M. TECA B - Treinamento de Emergências Cardiovasculares Básico da Sociedade Brasileira de Cardiologia. São Paulo: Editora Manole, 2012.

6. Travers AH, Perkins GD, Berg RA, Castren M, Considine J, Escalante R, et al. Part 3: Adult Basic Life Support and Automated External Defibrillation: 2015 International Consensus on Cardiopulmonary Resuscitation and Emergency Cardiovascular Care Science With Treatment Recommendations. Circulation. 2015;132(16 Suppl 1):S51-83.

7. Kleinman ME, Goldberger ZD, Rea T, Swor RA, Bobrow B, Brennan EE, et al. 2017 American Heart Association Focused Update on Adult Basic Life Support and Cardiopulmonary Resuscitation Quality: An Update to the American Heart Association Guidelines for Cardiopulmonary Resuscitation and Emergency Cardiovascular Care. Circulation. 2018;137(1):e7-e13.

8. Fredriksson M, Herlitz J, Nichol G. Variation in outcome in studies of outof-hospital cardiac arrest: a review of studies conforming to the Utstein guidelines. Am J Emerg Med. 2003;21(4):276-81.

9. Perkins GD, Brace SJ, Smythe M, Ong G, Gates S. Out-of-hospital cardiac arrest: recent advances in resuscitation and effects on outcome. Heart. 2012;98(7):529-35.

10. Blewer AL, Buckler DG, Li J, Leary M, Becker LB, Shea JA. Impact of the 2010 resuscitation guidelines training on layperson chest compressions. World J Emerg Med. 2015;6(4):270-6.

11. Smith KK, Gilcreast D, Pierce K. Evaluation of staff's retention of ACLS and BLS skills. Resuscitation. 2008;78(1):59-65.

12. Pande S, Pande S, Parate V, Pande S, Sukhsohale N. Evaluation of retention of knowledge and skills imparted to first-year medical students through basic life support training. Adv Physiol Educ. 2014 Mar;38(1):42-5.

\section{Fontes de financiamento}

O presente estudo não teve fontes de financiamento externas.

\section{Vinculação acadêmica}

Não há vinculação deste estudo a programas de pós-graduação.

\section{Aprovação Ética e Consentimento Informado}

Este estudo foi aprovado pelo Comitê de Ética da faculdade de Medicina do ABC sob o número de protocolo CAAE 81721317.0000.0082, parecer 2.559.797. Todos os procedimentos envolvidos nesse estudo estão de acordo com a Declaração de Helsinki de 1975, atualizada em 2013. O consentimento informado foi obtido de todos os participantes incluídos no estudo.

13. Leary M, Abella BS. The challenge of CPR quality: Improvement in the real world. Resuscitation. 2008;77(1):1-3.

14. Yang CW, Yen ZS, McGowan JE, Chen HC, Chiang WC, Manani ME, et al. A systematic review of retention of adult advanced life Support knowledge and sklis in healthcare providers. Resuscitation. 2012;83(9):1055-60.

15. de Ruijter PA, Biersteker HA, Biert].Retention of first aid and basic life support skills in undergraduate medical students. Med Educ Online. 2014;19:24841

16. Kleinman ME, Brennan EE, Goldberger ZD, Swor RA, Terry M, Bobeow BJ, et al. et al. Part 5: Adult basic life support and cardiopulmonary resuscitation quality: 2015 American Heart Association guidelines update for cardiopulmonary resuscitation and emergency cardiovascular care. Circulation. 2015;132(18 Suppl 2):414-35

17. Tipa RO, Bobirnac G, Davila C.Importance of basic life Support training for first and second year medical students, a personal statement. J Med Life. 2010;3(4):465-7

18. Bobirnac G, Abbas A, Bukhari SI,Ahmad F. Knowledge of first aid and basic life support amongst medical students: a comparison between trained and un-trained students. J Pak Med Assoc 2011;61:613-616.

19. Freund Y, Duchateau FX, Baker EC, Goulet H, Carreira S, Schmidt M, et al. Self-perception of knowledge and confidence in performing basic life support among medical students. Eur J Emerg Med. 2013;20(3):193-6.

20. Altintas, KH, Yildiz AN, Aslan D,Ozvaris SR, Behir N. First aid and basic life support training for first year medical students. Eur J Emerg Med. $2009 ; 16(6): 336-8$

21. Arthur W, Bennett W, Stanush PL. Factors that influence skill decay and retention: a quantitative review and analysis. Hum Perform. 1998;11:57-101.

22. Hamilton R. Nurses' knowledge and skill retention following cardiopulmonary resuscitation training: a review of the literature. J Adv Nurs. 2005;51(3):288-97.

23. Beom JH, You JS, Kim MJ,Seung MK, Park YS, Chung HS, et al. Investigation of complications secondary to chest compressions before and after the 2010 cardiopulmonary resuscitation guideline changes by using multi-detector computed tomography: a retrospective study. Scand J Trauma Resusc Emerg Med. 2017 Jan 26;25(1):8.

24. Thorne CJ, Lockey AS, Bullock I, Hampshire S, Begum-Ali S, Perkins GD Advanced Life Support Subcommittee of the Resuscitation Council (UK). E-learning in advanced life support--an evaluation by the Resuscitation Council (UK). Resuscitation. 2015;90:79-84. 